\title{
Emotional eating and Pavlovian learning: Does negative mood facilitate appetitive conditioning?
}

Citation for published version (APA):

Bongers, P., van den Akker, K., Havermans, R., \& Jansen, A. (2015). Emotional eating and Pavlovian learning: Does negative mood facilitate appetitive conditioning? Appetite, 89, 226-236. https://doi.org/10.1016/j.appet.2015.02.018

Document status and date:

Published: 01/06/2015

DOI:

10.1016/j.appet.2015.02.018

Document Version:

Publisher's PDF, also known as Version of record

Document license:

Taverne

Please check the document version of this publication:

- A submitted manuscript is the version of the article upon submission and before peer-review. There can be important differences between the submitted version and the official published version of record.

People interested in the research are advised to contact the author for the final version of the publication, or visit the DOI to the publisher's website.

- The final author version and the galley proof are versions of the publication after peer review.

- The final published version features the final layout of the paper including the volume, issue and page numbers.

Link to publication

\footnotetext{
General rights rights.

- You may freely distribute the URL identifying the publication in the public portal. please follow below link for the End User Agreement:

www.umlib.nl/taverne-license

Take down policy

If you believe that this document breaches copyright please contact us at:

repository@maastrichtuniversity.nl

providing details and we will investigate your claim.
}

Copyright and moral rights for the publications made accessible in the public portal are retained by the authors and/or other copyright owners and it is a condition of accessing publications that users recognise and abide by the legal requirements associated with these

- Users may download and print one copy of any publication from the public portal for the purpose of private study or research.

- You may not further distribute the material or use it for any profit-making activity or commercial gain

If the publication is distributed under the terms of Article $25 \mathrm{fa}$ of the Dutch Copyright Act, indicated by the "Taverne" license above, 
Research report

\title{
Emotional eating and Pavlovian learning: Does negative mood facilitate appetitive conditioning?
}

\author{
Peggy Bongers *, Karolien van den Akker, Remco Havermans, Anita Jansen \\ CPS, Department of Eating Disorders and Addiction, Faculty of Psychology and Neuroscience, Maastricht University, P.O. Box 616, Maastricht 6200 MD, The \\ Netherlands
}

\section{A R T I C L E I N F O}

\section{Article history:}

Received 21 August 2014

Received in revised form 5 February 2015

Accepted 11 February 2015

Available online 16 February 2015

\section{Keywords:}

Emotional eating

Appetitive conditioning

Mood

Impulsivity

Cue reactivity

\begin{abstract}
A B S T R A C T
Objective: Emotional eating has been suggested to be a learned behaviour; more specifically, classical conditioning processes might be involved in its development. In the present study we investigated whether a negative mood facilitates appetitive conditioning and whether trait impulsivity influences this process. Method: After undergoing either a negative or neutral mood induction, participants were subjected to a differential classical conditioning procedure, using neutral stimuli and appetizing food. Two initially neutral distinctive vases with flowers were $\left(\mathrm{CS}_{+}\right)$or were not $\left(\mathrm{CS}_{-}\right)$) paired with chocolate mousse intake. We measured participants' expectancy and desire to eat (4 CS+ and 4 CS- trials), salivation response, and actual food intake. The BIS-11 was administered to assess trait impulsivity. Results: In both mood conditions, participants showed a classically conditioned appetite. Unexpectedly, there was no evidence of facilitated appetitive learning in a negative mood with regard to expectancy, desire, salivation, or intake. However, immediately before the taste test, participants in the negative mood condition reported a stronger desire to eat in the CS+ compared to the CS- condition, while no such effect occurred in the neutral group. An effect of impulsivity was found with regard to food intake in the neutral mood condition: highimpulsive participants consumed less food when presented with the CS+ compared to the CS-, and also less than low-impulsive participants. Discussion: An alternative pathway to appetitive conditioning with regard to emotions is that it is not the neutral stimuli, but the emotions themselves that become conditioned stimuli and elicit appetitive responses.
\end{abstract}

(c) 2015 Elsevier Ltd. All rights reserved.

\section{Introduction}

Emotional eating (i.e., eating in response to negative emotions) is a contributing factor in obesity and eating disorders (Hays \& Roberts, 2008; Polivy \& Herman, 2002). Several studies have shown overeating after the experience of negative emotions, such as stress, anxiety or sadness, in dieters (Cools, Schotte, \& McNally, 1992; Heatherton, Herman, \& Polivy, 1991; Loxton, Dawe, \& Cahill, 2011; Wallis \& Hetherington, 2004), obese people (Patel \& Schlundt, 2001; Schneider, Appelhans, Whited, Oleski, \& Pagoto, 2010), and obese binge eaters (Agras \& Telch, 1998; Chua, Touyz, \& Hill, 2004). However, it is unknown how emotional eating originates or how it is maintained.

It has been suggested that emotional eating is a learned behaviour, as the natural response for most people in the face of adversity is to decrease food intake (Wardle, 1990). Specifically, classical or

\footnotetext{
Acknowledgements: This study is part of an ongoing project that is financed by the Netherlands Organisation for Scientific Research (NWO): Vici Grant 453.10.006, awarded to Anita Jansen.

* Corresponding author.

E-mail address: peggy.bongers@maastrichtuniversity.nl (P. Bongers).
}

Pavlovian conditioning has been proposed to be the involved mechanism (Greeno \& Wing, 1994; Jansen, 1998; Jansen, Havermans, \& Nederkoorn, 2011; Wardle, 1990). In classical conditioning, food intake is regarded as an unconditioned stimulus (US), eliciting unconditioned physiological responses (URs), such as insulin release, blood sugar increase and salivation. Over time, stimuli that are systematically paired with food intake can start to predict intake, thereby becoming conditioned stimuli (CS). After learning that the CS predicts the occurrence of the US, CSs are capable of eliciting appetitive responses, such as a conditioned desire to eat (i.e., cue reactivity). Virtually any stimulus in the environment can become a food-signalling CS, including the sight or smell of food, a certain time of the day, the environment or context (Jansen, 1998; Wardle, 1990 ) and it is also suggested that emotions can become foodsignalling CSs (Jansen et al., 2011).

Experimental studies indeed show that eating desires can be conditioned quite easily. Van Gucht and colleagues (Van Gucht, Baeyens, Hermans, \& Beckers, 2013; Van Gucht, Baeyens, Vansteenwegen, Hermans, \& Beckers, 2010; Van Gucht, Vansteenwegen, Beckers, \& Van Den Bergh, 2008; Van Gucht, Vansteenwegen, Van den Bergh, \& Beckers, 2008) and Papachristou, Nederkoorn, Beunen, and Jansen (2013) convincingly demonstrated appetitive conditioning to a neutral cue (i.e., a serving tray) in several studies, with participants 
reporting increased food expectancy, eating desire, and automatic approach tendencies when presented with the cue that predicted the intake of appetizing foods (CS+; a tray in one shape and colour) compared to the cue that did not predict the intake of appetizing foods (CS-; a tray in another shape and colour). Van den Akker, Jansen, Frentz, and Havermans (2013) extended these findings by showing appetitive conditioning in response to contexts (neutral environments in a virtual reality lab), indicating that besides specific cues, specific contexts can also come to elicit food expectancy and eating desire after the context becomes a predictor of intake. In addition to expectancy and desire, Van den Akker et al. (2013) also measured salivation and actual food intake. They found increased saliva production in participants presented with the CS+, but not the CScontext. Thus, after only 6 pairings of a neutral context with the intake of appetizing food, some evidence was found that participants salivated more in the context that predicted the intake compared to a context that did not predict intake. The authors also found that food intake increased in the CS+ compared with the CS- contexts, but only for participants high in impulsivity. This effect of impulsive people showing increased conditioned food intake is interesting, considering the wealth of research showing a positive association between impulsivity on the one hand and food consumption and obesity on the other hand (see Guerrieri, Nederkoorn, \& Jansen, 2008 for an overview; Velázquez-Sánchez et al., 2014). Importantly, a role for impulsivity in appetitive conditioning was proposed by Gray (Corr, Pickering, \& Gray, 1995) in his BIS/BAS theory, which predicted that high impulsivity (i.e., strong BAS; Behavioural Approach System) is related to increased associative appetitive learning, while high anxiety (i.e., strong BIS; Behavioural Inhibition System) is related to increased aversive learning. Research with regard to the facilitating role of impulsivity in appetitive learning has however yielded mixed results (Corr, 2004; Corr et al., 1995; Paisey \& Mangan, 1988; Papachristou et al., 2013; Van den Akker et al., 2013; Zinbarg \& Mohlman, 1998; Zinbarg \& Revelle, 1989) and studies specifically on food as the appetitive stimulus are scarce (Papachristou et al., 2013; Van den Akker et al., 2013).

If emotional eating is, as we suggest, learned through classical conditioning, two pathways through which this could occur are most obvious. First, it is frequently reported by emotional eaters that they overeat when feeling bad. If a particular emotional state is frequently associated with the intake of appetizing high calorie foods, and the contingency between this emotion and eating is strong (i.e., the probability of the emotion leading to eating approaches one), this association will ultimately lead to the emotion becoming a reliable predictor of food intake, i.e., a CS. After conditioning, confrontation with the CS (emotion) will elicit cue reactivity, i.e., an eating desire or food craving, and ultimately food intake. An alternative pathway is negative mood facilitating the learning of associations between neutral stimuli and food intake. Highcalorie foods have strong rewarding properties (see for example Coletta et al., 2009; Macht \& Dettmer, 2006; Macht \& Mueller, 2007; Small, Zatorre, Dagher, Evans, \& Jones-Gotman, 2001), which might be extra rewarding and thus relevant for people who find themselves in a negative emotional state (Baker, Piper, McCarthy, Majeskie, \& Fiore, 2004; Hepworth, Mogg, Brignell, \& Bradley, 2010). They would benefit from learning that certain cues predict food intake that might alleviate their bad mood. In this model, a neutral stimulus from the environment, or the environment itself, becomes the $\mathrm{CS}$. The CS predicts food intake and as a consequence of the rewarding foods, a better mood. This pattern might be considered a specific form of state-dependent learning or context learning, in which the negative mood functions as a state or context. Furthermore, research in fear conditioning has brought forward some evidence that negative contexts (i.e., threat) facilitate conditioning (Karos, Meulders, \& Vlaeyen, 2014). The latter pathway is the one under investigation in the current study.
In the present study, we tested the hypothesis that participants in a negative mood would show facilitated appetitive conditioning. We expected stronger differential responses to the CSs for the group that was conditioned in a negative mood compared to the group that was conditioned in a neutral mood: those in a negative mood would show a larger difference in expectancies to receive food, desires to eat food, saliva production, and food intake in response to the CS predicting the intake of high-caloric food (CS+) than to the CS not predicting food intake (CS-). Because impulsivity is strongly related to overeating and obesity and earlier research shows that highly impulsive participants in particular eat more after classical conditioning (Van den Akker et al., 2013), we investigated the possibility of a moderating effect of impulsivity on expectancy, desire, salivation and food intake, with higher levels of impulsivity facilitating conditioning.

\section{Methods}

\section{Participants}

A total of 127 female undergraduate students, aged between 17 and 30 years $(M=19.98, S D=1.79)$, took part in the study. The students were told that the study concerned examining the relationship between music and taste. To be included, participants had to like chocolate mousse (the food of choice in the current study; scoring at least 3 on a 5-point Likert scale ranging from 'I do not like chocolate mousse at all' (1) to 'I really like chocolate mousse' (5)), which was assessed with a single question among four filler questions during sign up. They were instructed to eat something small (e.g., a sandwich or an apple) 2 hours before the start of the experiment, and to refrain from food intake (with the exception of water) in the time thereafter. Furthermore, they were asked not to eat any chocolate in the 24 hours before participating. For participation, participants received either one course credit, or $€ 7.50$. The study's procedure was approved by the local ethics committee. At the end of the study, when all testing was completed, participants received a debriefing via email containing an explanation of the aims and measures of the study.

\section{Design}

The study used a mixed design. Participants were randomly divided over 2 conditions: negative mood and neutral mood (from hereon called Negative and Neutral, respectively). Within these conditions, participants were divided into two groups for the postconditioning saliva measurement and taste test. Half of the group in each mood condition received these measurements in presence of the CS+ (from here on called 'Negative CS+' and 'Neutral CS+'), while the other half received them in presence of the CS- (from here on called 'Negative CS-' and 'Neutral CS-'). Mood, expectancy to receive food and desire to eat were within-subject variables, measured 8 times for each participant (4 times in response to CS+, 4 times in response to $\mathrm{CS}-$ ). Saliva production was an additional withinsubject variable, measured at baseline and at the end of the conditioning procedure (for half the participants in presence of the $\mathrm{CS}+$, for the other half in presence of the CS-).

\section{Stimuli}

\section{Mood manipulation}

After sign-up, the participant was instructed to bring at least three pieces of music (lasting for a minimum of 8 minutes) that made her happy and three pieces of music that made her sad (also totalling at least 8 minutes) with her to the lab. Participants were randomly assigned to either the neutral or negative condition. To induce a negative mood, the participant was asked to think of a sad 
event that happened to her. When she had something in mind, the sad songs chosen by the participant were played and she was given a blank sheet of paper and asked to write down that memory as detailed as possible. If she finished writing before the experimenter returned, she was instructed to keep thinking about the event she had written about. She was told that her memory would not be read by the experimenter. All stories were anonymously checked by an independent rater (A.J.) however, and this check confirmed that all participants had followed the instructions. In the neutral mood procedure, the participant was asked to write down the route she travelled from her home to the university library, and when she got there, which steps she would need to copy pages from a book. In the neutral condition, this assignment was accompanied by the musical piece De l'aube à midi sur la mer by Claude Debussy (playing time: 8 min 53 s). Vuoskoski and Eerola (2012) reported that personally relevant sad music combined with the recollection of sad autobiographical memories is an effective way of inducing sad moods. In addition, they found De l'aube à midi sur la mer did not change participants' emotions. Total duration of the mood manipulation was 8 minutes. Shorter versions of the mood manipulation were repeated after trials 4 and 7 of conditioning, to ensure that the participant remained in the required mood. During these inbetween manipulations, participants continued writing down or thinking about their memory for 1 minute, while the sad or neutral music played. The personally selected pieces of happy music were only used at the end of the experiment to counteract possible lingering negative feelings.

\section{US and CSS}

Plastic teaspoons with approximately $2 \mathrm{~g}$ of chocolate mousse (Almhof) were used as USs. A round green vase with three artificial red roses and a rectangular orange vase with three artificial white daisies were used as CSs. One of these vases served as CS+ and the other as CS-, and this was counterbalanced across participants. Four $\mathrm{CS}+$ and four CS- trials were presented to each participant. The order of the trial presentation was random, with the restriction that the first two trials always consisted of one CS+ and one CS-, counterbalanced across participants. Furthermore, there were no more than two consecutive trials of the same type (CS+ or CS-).

\section{Measures}

\section{Hunger}

Hunger was measured before and after the mood manipulation by means of a $100 \mathrm{~mm}$ Visual Analogue Scale (VAS). Participants had to answer the question 'How hungry are you at this moment?', with the left anchor of the scale corresponding to 'not hungry at all' and the right anchor to 'very hungry'.

\section{Expectancy and desire}

Expectancy to receive chocolate mousse and desire to eat chocolate mousse were assessed with 100 mm VASs. Expectancy was measured with the question 'How strongly do you expect to receive chocolate mousse at this moment?', with the scale ranging from 'no expectancy at all' to 'very strong expectancy'. For desire, the question was 'If you concentrate on the vase with flowers, how strong is your desire to eat chocolate mousse?' Ratings ranged from 'no desire at all' to 'very strong desire'. Identical desire-VASs were administered before and after the mood manipulation (for eating in general) and before the taste test (specifically aimed at eating chocolate mousse).

\section{CS liking}

Liking for the CS was measured in two different ways. Upon the first encounter with each CS, participants filled out a VAS scale asking 'How pleasant do you find this vase with flowers?', with answers ranging from 'not pleasant at all' to 'very pleasant'. This question was repeated for both CSs after the last conditioning trial. In addition, participants were asked to imagine that they were allowed to take one of the flower vases home, and they had to indicate which of the two they preferred.

\section{Contingency awareness}

To check whether participants were aware of the contingency between CS+ and chocolate mousse consumption, they were asked 'Was there a specific vase with flowers after which you were always asked to eat chocolate mousse?' If participants answered this question with 'yes', they were asked to indicate which vase was always followed by food intake. Other answering options were 'no' and 'I don't know'.

\section{Saliva}

Saliva production was measured with 2.5 cotton dental rolls (Hartmann Celluron no. 2), which were weighed beforehand on a kitchen scale ( $0.01 \mathrm{~g}$ precision) and presented to the participant in a small plastic bag. Participants placed the two whole rolls between their cheek and lower gum on each side of the mouth, and an additional half dental roll under the tongue. The rolls were removed after one minute, replaced in the bag, and weighed again.

\section{Taste test and food intake}

The taste test consisted of 3 identical small bowls each filled with approximately $74.13(\mathrm{SD}=5.97)$ grams of chocolate mousse. The bowls were brought into the testing room by the experimenter, together with either the CS+ or CS- vase with flowers (which was counterbalanced across participants), and placed on the table in front of the participant. She was told there were some small differences between the three types of mousse that she had to detect (in fact they were all identical and the same as the mousse used during conditioning), in order to stimulate her to really try and taste from all the bowls. She received a short questionnaire regarding taste and structure of the three bowls of chocolate mousse, and was told she had 5 minutes to answer the questions, and that the experimenter would return once that time had passed. Unbeknownst to the participant, the bowls were weighed before and after the taste test to assess chocolate mousse consumption.

\section{Chocolate mousse liking}

Three of the questions incorporated in the taste test questionnaire measured liking of the chocolate mousse. For each of the three bowls, participants rated the mousse on a 5-point Likert scale, ranging from 'I do not like this mousse at all' to 'I like this mousse very much'. The remaining questions were not used for analyses.

\section{Mood}

Two $100 \mathrm{~mm}$ VASs were used to assess mood, one measuring sadness and one measuring happiness. They stated 'how sad/ happy do you feel at this moment?' and ranged from 'not at all' to 'very much'. In addition, a similar question regarding boredom was administered to be able to check whether boredom during conditioning possibly influenced the sad and happy mood ratings.

\section{$D E B Q(E E$ and $D R$ )}

The Emotional Eating (EE) and Dietary Restraint (DR) subscales of the Dutch Eating Behavior Questionnaire (DEBQ; Van Strien, 2005) were used to measure emotional eating and dietary restraint. The subscales consist of 13 and 10 items, respectively, and answers are given on a five-point Likert scale ranging from 'never' to 'very often'. Final scores on each DEBQ subscale range from 1 to 5 , with higher scores pointing to a higher degree of emotional eating or dietary behaviour. 
BIS-11

The Barratt Impulsiveness Scale - 11 (Patton, Stanford, \& Barratt, 1995 ) measures impulsivity through a 30 -item self-report questionnaire. Items have to be answered on a 4-point scale, with higher total scores reflecting higher levels of impulsivity. Only total score on the BIS-11 was included in analyses. Patton et al. (1995) reported that the BIS-11 has high internal consistency.

\section{Compliance to eating instructions}

Participants were asked to report what and when they had last eaten before participating in the experiment. In addition, they were asked whether they had consumed any chocolate in the past 24 hours, and if yes, when exactly this had occurred.

\section{Procedure}

Upon arrival in the laboratory, the participant was seated at a table and signed an informed consent form. A baseline saliva measure was conducted, and she then filled out VASs concerning mood, hunger and desire to eat. This was followed by either the neutral or negative mood manipulation, and then again the mood, hunger and desire to eat VASs. At this point, the conditioning procedure started. The participant was informed that she would now be presented with vases with flowers, and that one of the vases would always be followed by something to eat, while the other one would not. The first vase was then taken from a large bag hidden underneath the table and placed on the table in front of the participant. She was instructed to concentrate on the vase and flowers for 10 seconds, and then received the VASs for desire, expectancy, and CS liking. From a closed box placed on the table, the experimenter then took out a small cup containing either a spoon filled with chocolate mousse or an empty spoon, depending on whether the vase was determined to be CS+ or CS-. In the case of CS+, the participant was instructed to eat the chocolate mousse. In case of the CS-, the experimenter told her that because the spoon was empty, no eating would occur. The spoon and vase were placed back in the box and bag respectively, and a 45-second intertrial interval followed, during which the participant received the mood VASs to fill out. This sequence of events was repeated randomly 8 times, 4 times with a CS+ and 4 times with a CS-. After trials 4 and 7, one-minute mood manipulations took place. During trial 8, after being presented with the CS+ or CS- and filling out the VASs for expectancy and desire, but before receiving (or not receiving) chocolate mousse, a second saliva measurement was performed. After finishing the conditioning trials, the participant filled out the questions regarding CS liking. The experimenter then brought in the bowls of chocolate mousse for the taste test together with the CS+ or CS-. The participant rated her desire to eat the mousse, and was left alone to taste. The chocolate mousse was taken away after 5 minutes and the participant filled out the contingency VAS. The participant then filled out the DEBQ BIS-11 and questions regarding compliance to eating instructions while listening to her selected happy songs. Finally, her height and weight were measured wearing street clothes and no shoes, and she was reimbursed for participation.

\section{Statistical analyses}

Six participants were excluded because they did not report contingency awareness, as there is a wide consensus among conditioning researchers that contingency learning and contingency awareness are necessary for conditioning to occur (Boddez et al., 2013; Lovibond \& Shanks, 2002). One additional participant was excluded for not bringing her own music to the lab. With regard to chocolate intake, 115 participants complied with the instructions and had not eaten chocolate for 24 hours, 4 participants had eaten chocolate but on the previous day, and one participant reported eating chocolate on the day of the experiment. We reanalyzed our data excluding the 5 participants who did not comply with our instructions. Because this did not change our results, we reported analyses based on all 120 participants, with the exception of analyses including saliva measurements, which were performed on 118 participants due to missing data.

To investigate the effect of the mood manipulation, a 2 (Condition: negative vs neutral) $\times 10$ (Time: baseline, post-manipulation, 8 measurements during conditioning) mixed ANOVA was conducted. To control for dietary restraint, and to check for influences of impulsivity and emotional eating on acquisition, DEBQ emotional eating, DEBQ dietary restraint, and BIS-11 scores were included as covariates in all following ANCOVAs. Given that there were no a priori hypotheses with regard to emotional eating and dietary restraint, $\alpha$ was adjusted to .008 (for analyses on expectancy and desire) or .016 (for all other analyses) to correct for the number of interactions tested among these variables.

Differential acquisition of expectancy and desire to eat chocolate mousse was measured through mixed 2 (Condition: negative vs. neutral $) \times 2($ CS-type: CS+ vs. CS- $) \times 4$ (Trial: $1,2,3,4)$ ANCOVAs. Changes in liking of the CSs were investigated by a 2 (Condition: negative vs. neutral $) \times 2$ (CS type: $C S+$ vs. $C S-) \times 2$ (Time: baseline, post-conditioning) mixed ANCOVA. A binomial test was used to assess preference of CS+ over CS-. A 2 (Condition: negative vs. neutral $) \times 2$ (CS-type: $C S+$ vs. $C S-) \times 2$ (time: baseline, trial 4$)$ mixed ANCOVA was conducted to analyze saliva production. With regard to all repeated measures analyses, Greenhouse-Geisser corrections are reported when sphericity was violated.

Desire to eat immediately before the taste test and food intake (in grams) were first analyzed in a 2 (Condition: negative vs. neutral) $\times 2$ (CS-type: CS+ vs. CS-) ANCOVA. Subsequently we performed moderated regression analyses with simple slope testing and spotlight-analyses at one standard deviation above or below the mean of the BIS- 11 for the neutral and negative conditions separately, to investigate the moderating role of impulsivity on chocolate mousse consumption. Chocolate mousse intake was the dependent variable and condition and BIS-11 scores the independent variables. In all analyses, DEBQ Emotional Eating scores and DEBQ Dietary Restraint scores were entered as covariates in the first block. In the second block, CS type (CS- vs. CS+ with CS- coded as reference group) and BIS-11 score were added. In the third and final block, the interaction between the two variables of the second block was entered. Variables were centred prior to entering them in the regression model. As indicated by Variance Inflation Factors (always close to 1 ) and Tolerance (never below 0.2 ), there were no multicollinearity problems in any of the conducted regressions. In addition, the Durbin-Watson statistic had a value close to 2 in all analyses, indicating that the assumption of independence of errors was met. P-values below 0.05 were considered significant.

\section{Results}

\section{Group characteristics}

As shown in Table 1, the participants in the four conditions did not differ on age, BMI, BIS-11 scores, DEBQ emotional eating, DEBQ dietary restraint, baseline mood (i.e., happiness and sadness), minutes since last eaten, or baseline hunger. However, a difference in hunger did emerge after the mood manipulation. Direct comparison between hunger and desire to eat in the negative and neutral mood conditions yielded significant differences, $F(1,119)=14.10, p<.001$ and $F(1,119)=30.87, p<.001$, respectively.

\section{Mood manipulation}

Condition $\times$ Time repeated measures ANOVAs showed that the mood induction was successful, as indicated by significant Condition $\times$ Time interactions on both sadness $F(6.08,717.64)=52.53, p<.001$ (see Fig. 1a) and happiness $F(6.91,815.70)=21.49, p<.001$ (see Fig. 1 b). 
Table 1

Mean and standard deviation of participant characteristics per condition.

\begin{tabular}{|c|c|c|c|c|c|c|c|c|c|c|}
\hline & \multicolumn{2}{|c|}{ Negative $C S+(n=30)$} & \multicolumn{2}{|c|}{ Negative CS- $(\mathrm{n}=31)$} & \multicolumn{2}{|c|}{ Neutral CS $+(n=30)$} & \multicolumn{2}{|c|}{ Neutral CS- $(\mathrm{n}=29)$} & \multirow[t]{2}{*}{$\mathrm{F}$} & \multirow[t]{2}{*}{$p$} \\
\hline & $\mathrm{M}$ & SD & $\mathrm{M}$ & SD & $\mathrm{M}$ & SD & M & SD & & \\
\hline Age & 19.90 & 1.75 & 20.00 & 1.59 & 20.03 & 2.27 & 19.97 & 1.57 & .03 & .99 \\
\hline BMI & 22.04 & 3.04 & 22.35 & 3.18 & 22.70 & 4.34 & 22.25 & 2.65 & .20 & .90 \\
\hline BIS-11 & 62.87 & 9.87 & 61.35 & 10.44 & 63.80 & 8.64 & 64.21 & 10.24 & .50 & .68 \\
\hline DEBQ-EE & 2.61 & .64 & 2.66 & .67 & 2.71 & .57 & 2.98 & .54 & 2.21 & .09 \\
\hline DEBQ-DR & 2.53 & .96 & 2.95 & .73 & 2.87 & .83 & 2.68 & .81 & 1.57 & .20 \\
\hline Sadness & 13.40 & 15.97 & 10.23 & 9.03 & 15.83 & 11.29 & 12.03 & 13.48 & 1.06 & .37 \\
\hline Happiness & 65.07 & 17.32 & 68.13 & 15.92 & 65.30 & 10.66 & 67.59 & 14.07 & .34 & .80 \\
\hline Minutes since eatinga & 157.00 & 40.34 & 155.97 & 46.86 & 142.86 & 40.74 & 151.85 & 27.04 & .76 & .52 \\
\hline Hunger baseline & 53.40 & 22.17 & 48.77 & 22.15 & 49.67 & 17.03 & 52.66 & 21.20 & .36 & .79 \\
\hline Hunger after manipulation & 40.03 & 23.35 & 39.58 & 20.02 & 52.87 & 18.82 & 54.03 & 17.48 & 4.64 & .004 \\
\hline Desire baseline & 62.43 & 16.84 & 58.97 & 19.58 & 63.60 & 15.12 & 63.97 & 15.78 & .55 & .65 \\
\hline Desire after manipulation & 41.07 & 19.08 & 40.23 & 21.25 & 60.30 & 16.98 & 58.83 & 17.53 & 10.17 & .000 \\
\hline
\end{tabular}

${ }^{\text {a }}$ For the Neutral CS+ and Neutral CS- conditions, analyses are based on the data of 28 and 27 participants, respectively.

\section{US expectancy}

With regard to US expectancy, a mixed Condition $\times$ CS-Type $\times$ Trial ANCOVA revealed a significant CS-type $\times$ Trial interaction, $F(2.06$, 230.76) $=180.63, \mathrm{p}<.001$, confirming differential acquisition of US expectancy in response to CS+ or CS-. Thus, participants learned to expect food when confronted with the CS+, and to not expect food when confronted with the CS- (see Fig. 2). There was no influence of impulsivity on differential expectancy over time, $F(2.06$, $230.76)=.67, p=.52$. The Condition $\times$ CS-type $\times$ Trial interaction was not significant, $F(2.06,230.76)=.45, p=.64$, indicating no differences in acquisition of US expectancy between the negative and neutral conditions. Impulsivity did again not exert any influence on this interaction, $F(2.06,230.76)=1.27, p=.28$.

US desire

The ANCOVA on desire to eat chocolate mousse also showed differential acquisition through a significant Condition $\times$ CS-type $\times$ Trial interaction, $F(2.78,311.49)=4.08, p=.009$, indicating differences between the conditions in the acquisition of desire (see Fig. 3): participants in the neutral mood condition showed a different pattern of desire than the participants in the negative mood condition. To investigate the differences in acquisition, a CS-Type $\times$ Condition
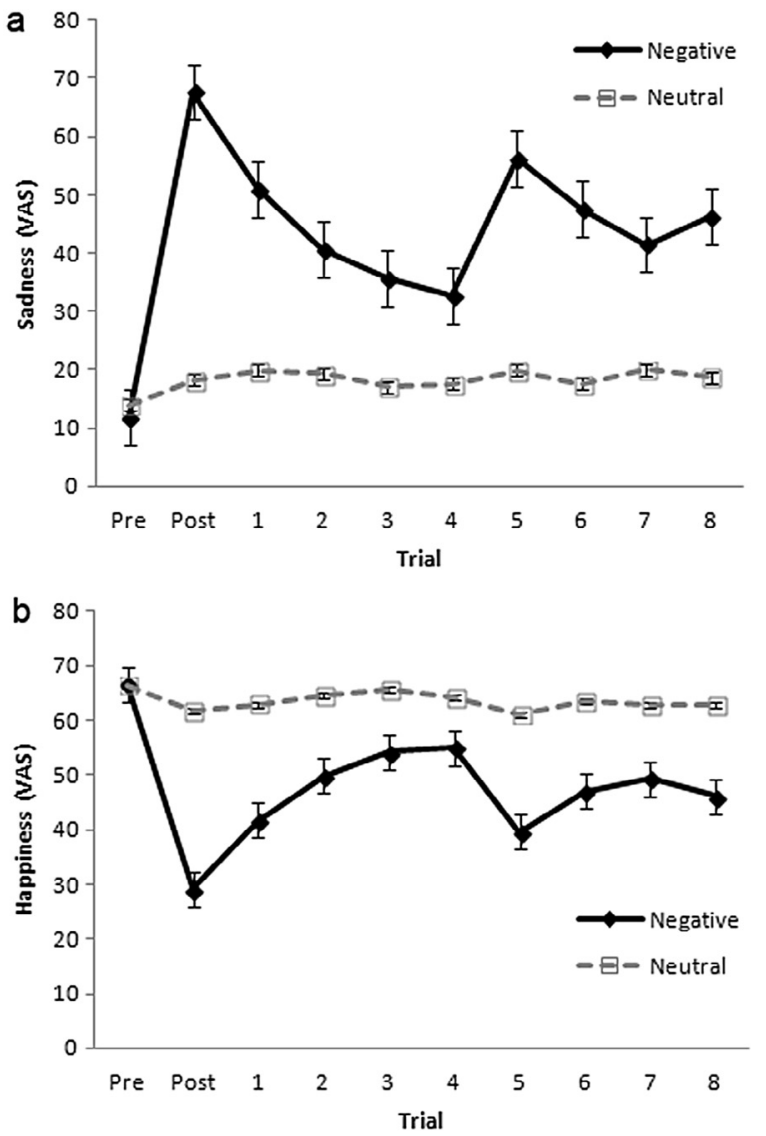

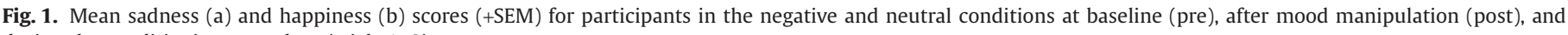
during the conditioning procedure (trials $1-8$ ). 


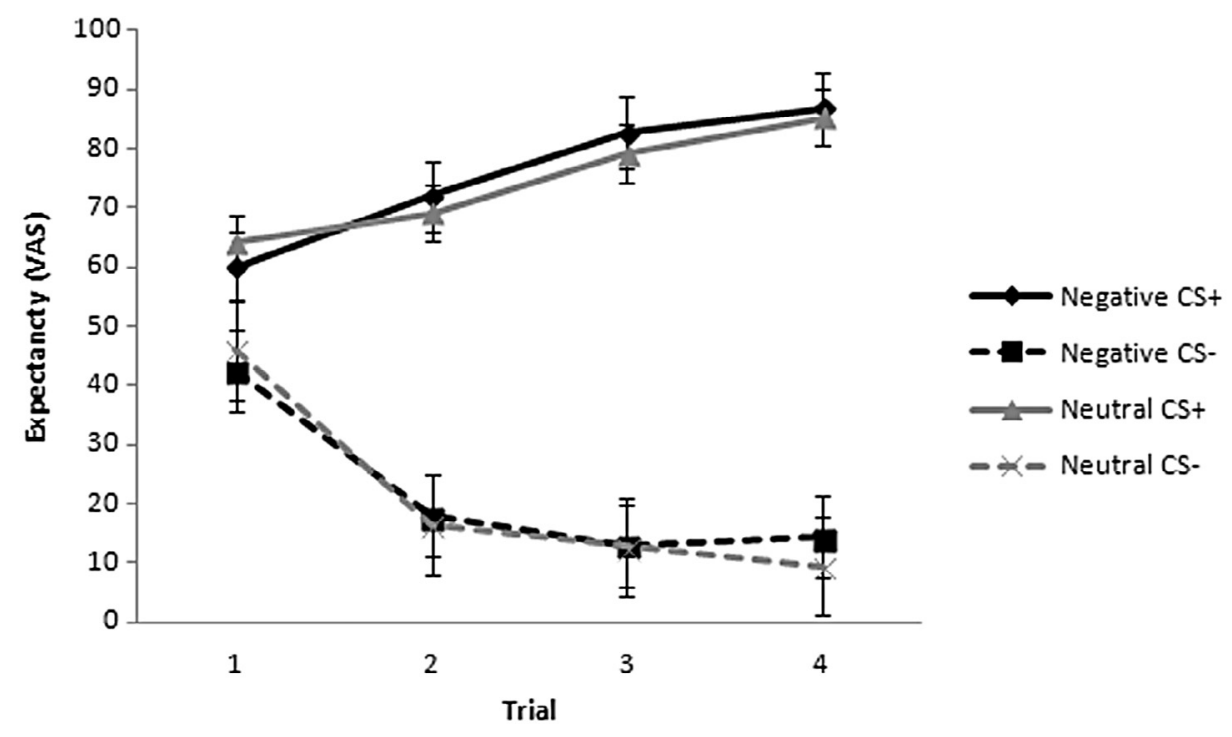

Fig. 2. Mean US expectancy scores (+SEM) by CS-type and trial, for the negative and neutral conditions separately.

interaction was computed for trials 2,3 and 4 . There was no significant CS-Type $\times$ Condition interaction at trial $2, F(1,115)=.24$, $p=.62$, or trial $3, F(1,115)=2.55, p=.11$, but at trial 4 differential desire to eat was significantly smaller for the negative compared to the neutral condition $F(1,115)=5.48, p=.021$, indicating a less strong conditioning of desire for people in a negative than in a neutral mood. However, at trial 4 participants in the negative condition still reported higher desire in response to the CS+ than the CS-, $t(60)=3.74, p<.001$. So, successful conditioning of desire to eat was observed in both conditions. Impulsivity did not influence differential acquisition of desire to eat, CS-Type $\times$ Trial $\times$ Impulsivity, $F(2.78$, $311.49)=.11, p=.95$ and Condition $\times$ CS-Type $\times$ Trial $\times$ Impulsivity, $F(2.78,311.49)=1.77, p=.16$.

Taken together, our conditioning procedure was successful. However, participants in a negative mood did not show facilitated appetitive conditioning as measured by expectancy or desire compared to participants in a neutral mood. In fact, at the end of the conditioning procedure, conditioned desire to eat was significantly lower in the negative mood compared to the neutral mood group. Conditioned expectancy to eat did not differ between groups.

\section{CS liking}

A Condition $\times$ CS-type $\times$ Time mixed ANCOVA yielded a significant CS-type $\times$ Time interaction, $F(1,112)=104.05, p<.001$, indicating a change in differential liking of the CS+ vs. CS- during conditioning. As expected, no differences in CS liking were found between the two mood conditions, as shown by a non-significant threeway interaction, $F(1,112)=1.06, p=.31$. Overall, liking for the CS+ increased slightly and almost reached statistical significance (baseline $\mathrm{M}=67.31, \mathrm{SD}=18.14$, post $\mathrm{M}=70.40, \mathrm{SD}=15.18, F(1$, $116)=3.86, p=.052)$. Liking for the CS- decreased significantly over time (baseline $M=65.38, S D=17.74$, post $M=43.38, S D=19.47$, $F(1,116)=151.28, p<.001)$. Thus, mostly as a consequence of a significant decrease in liking of the CS-, the CS+ was more liked than the CS- in both mood conditions after conditioning.

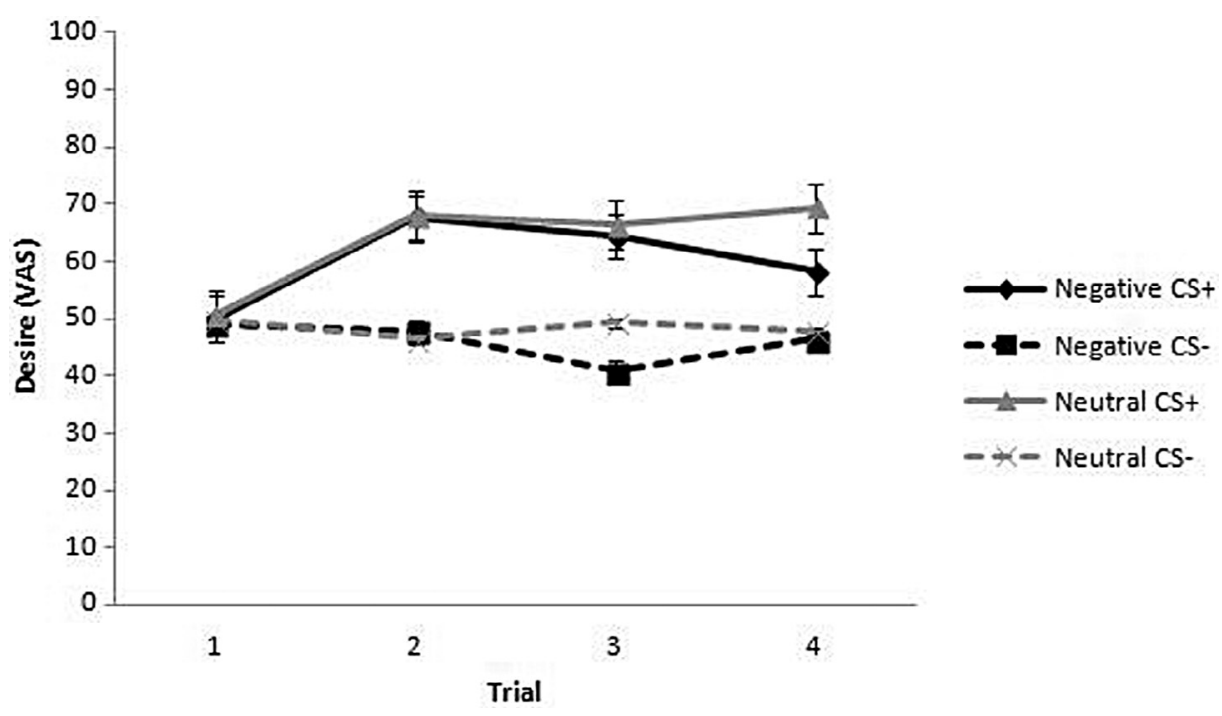

Fig. 3. Mean US desire scores (+SEM) by CS-type and trial, for the negative and neutral conditions separately. 
There was no effect of impulsivity on differential CS liking for either the Time $\times$ CS-Type interaction, $F(1,112)=1.62, p=.21$ or the Time $\times$ CS-Type $\times$ Condition interaction, $F(1,112)=.38, p=.57$. With regard to CS preference, the CS+ was chosen by $79 \%(n=95)$ $(p<.001)$ of the participants. These data again show successful conditioning, with a difference in liking of the CS+ and CS- emerging after conditioning, but no significant differences between conditions.

Saliva

A Condition $\times$ CS-Type $\times$ Time mixed ANCOVA revealed a main effect of CS-type $F(1,102)=4.04, p=.047$, indicating higher salivation in response to the $\mathrm{CS}+(M=.97, S D=.08)$ than the CS- $(M=.74, S D=.08)$. Furthermore, a main time effect for salivation was found, $F(1,102)=27.37, p<.001$, but no CSType $\times$ Time interaction, $F(1,102)=2.35, p=.13$, nor a Condition $\times$ CS-Type $\times$ Time interaction, $\mathrm{F}(1,102)=1.53, p=.22$. Impulsivity did not exert any influence on salivation, $F(1,102)=.13$, $p=.72$. The salivation data are depicted in Fig. 4. Our hypothesis that participants in a negative mood would produce a stronger conditioned salivation response than participants in a neutral mood when presented with the CS+ could not be confirmed.

\section{Desire to eat before taste test}

An ANCOVA on reported desire to eat when presented with the three bowls of chocolate mousse just before the taste test revealed no significant main effect of Condition, $F(1,104)=.70, p=.40$. However, there was a significant main effect of CS-type, $F(1$, $104)=5.43, p=.02$, as well as a significant Condition $\times$ CS-Type interaction, $F(1,104)=4.10, p=.045$. The participants in a negative mood showed more desire to eat when being in the presence of the CS+ compared to the CS-, whereas participants in a neutral mood did not (Negative CS+: $M=75.13, S D=16.41$; Negative CS-: $M=60.00$, $S D=23.27, F(1,60)=8.56, p=.005$; Neutral $C S+: M=70.33, S D=21.73$; Neutral CS-: $M=69.93, S D=19.56, F(1,58)=.006, p=.94)$. Although there was no Condition $\times$ CS-Type interaction with impulsivity, $F(1,104)=1.02, p=.32$, there was a significant interaction with dietary restraint, $F(1,104)=6.16, p=.015$ (adjusted $\alpha=.016)$. A moderated regression analysis showed no difference in desire to eat in presence of the CS+ or CS- between people high and low in restraint when in a neutral mood, CS-Type $\times$ Dietary Restraint $\beta=.06, t(58)=.29, p=.78$. However, in a negative mood, high and low restrained eaters did not differ in desire to eat in presence of the CS-, but did so in presence of the CS+, CS-Type $\times$ Dietary Restraint $\beta=-.60, t(60)=-2.98, p=.004$. Specifically those low in restraint reported a higher desire to eat when the CS+ was present.

\section{Food intake}

With regard to food intake, there was no main effect of mood condition, $F(1,104)=.002, p=.97$, and no main effect of CS-Type, $F(1,104)=.05, p=.83$. The Condition $\times$ CS-Type interaction was also not significant, $F(1,104)=1.57, p=.21$. These results indicate that participants consumed the same amount of food, irrespective of mood or CS-Type (Negative CS+: $M=69.94, S E=6.53$; Negative CS-: $M=60.21, S E=6.40$; Neutral CS+: $M=61.34, S E=6.31$; Neutral CS-: $M=68.13, S E=7.10)$. We did however find a 3-way interaction between Condition, CS-Type, and Impulsivity, $F(1,104)=4.08$, $\mathrm{p}=.046$, suggesting that degree of impulsivity influences food intake after appetitive conditioning in a neutral vs. negative mood.

\section{Impulsivity and food intake}

To follow-up on the significant 3-way interaction, CS-Type $\times$ Impulsivity interactions were conducted for the two mood conditions. For the neutral condition, the analysis showed a significant interaction between CS-Type and BIS-11 score, $\beta=.44, t(58)=2.35$, $p=.023$, indicating that intake in response to the CS+ and CS- is dependent on degree of impulsivity. More specifically, and contrary to expectations, at high levels of impulsivity, chocolate mousse intake was significantly lower when the CS+ was present than when the CS- was present, $\beta=-.46, t(58)=-2.62, p=.011$. At low levels of impulsivity, food intake in response to the CS+ and CS- did not differ, $\beta=.13, t(58)=.70, p=.49$. Furthermore, within the Neutral CS+ group, food intake was significantly lower for high impulsive compared to low impulsive participants, $\beta=-.55, t(58)=-2.83, p=.006$, whereas there was no such difference within the Neutral CS- group, $\beta=.04$, $t(58)=.22, p=83$.

With regard to the negative condition, no significant effects of CS-Type and impulsivity on mousse intake were found, $\beta=.23$, $t(60)=1.27, p=.21$. Within the high impulsive and low impulsive groups there were no differences in intake in response to the CS+ or CS-, and there was no effect of impulsivity on intake within the

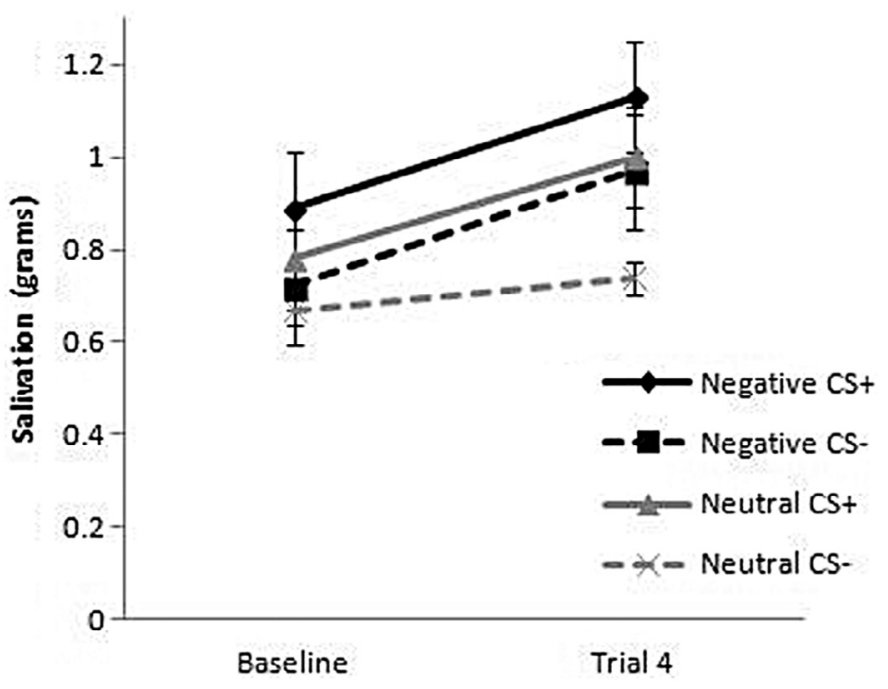

Fig. 4. Mean salivation in grams at baseline and after the conditioning procedure for all four conditions separately. 


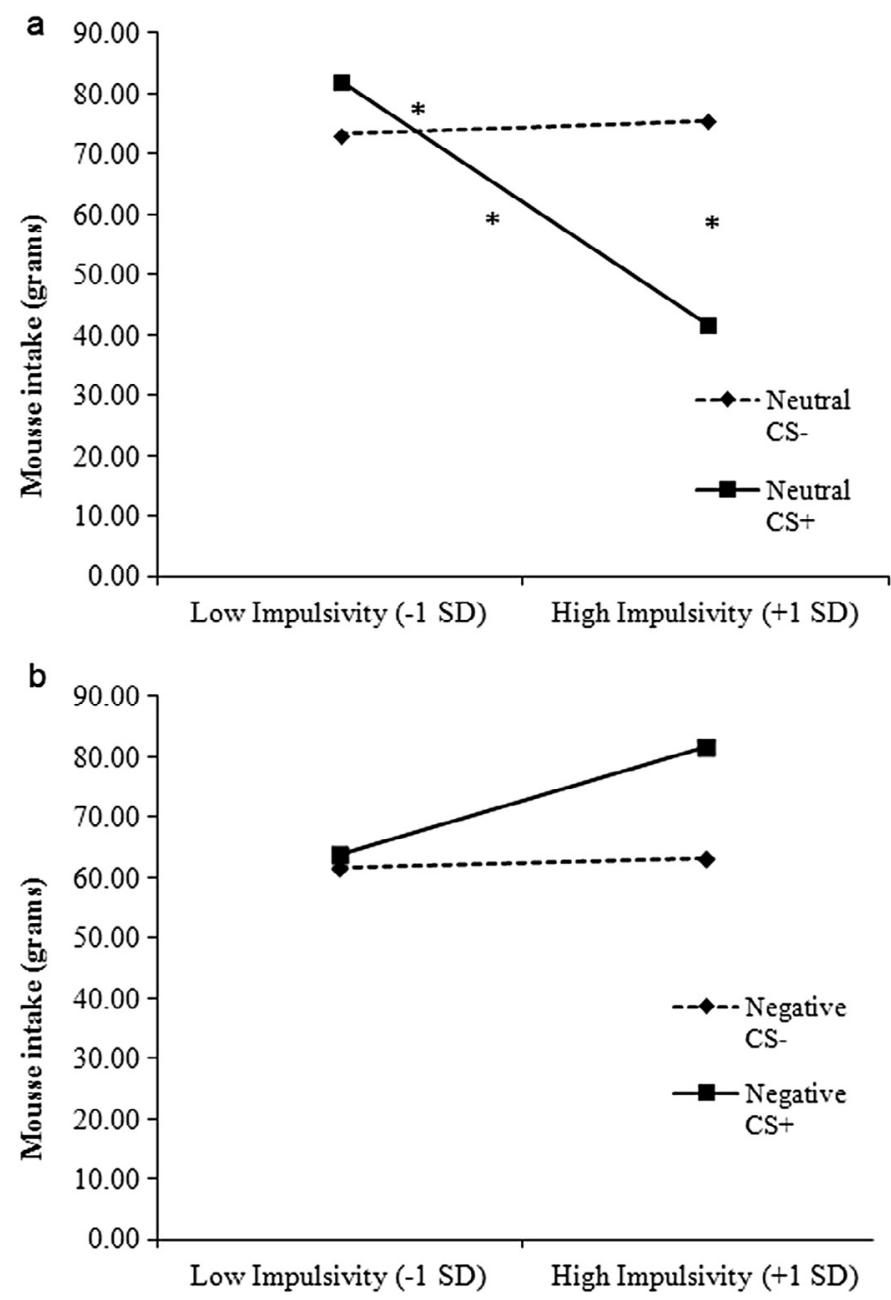

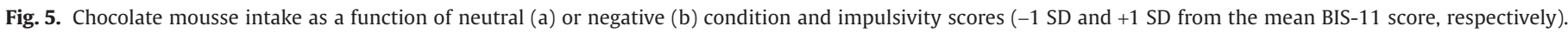
The asterisks indicate the significant effects.

Negative CS+ and Negative CS- groups, all beta weights, $p>.13$. In short, whereas impulsivity moderated CS-related food intake in the neutral condition, this was not true for the negative condition. Simple slopes and interactions with standardized regression coefficients for participants scoring high (+1 SD) and low ( $-1 \mathrm{SD})$ on impulsivity are plotted in Fig. 5a (neutral condition) and 5b (negative condition). Results of both regression analyses can be found in Table 2 .

\section{Discussion}

In the current study we took a first step in shedding light on the origin of emotional eating by testing whether classical conditioning processes might be involved. More specifically, we investigated whether being in a negative mood facilitates appetitive conditioning, as measured by the expectancy to eat, desire to eat, saliva

Table 2

Results of moderated regression analysis of condition and BIS-11 scores on chocolate mousse intake.

\begin{tabular}{|c|c|c|c|c|c|c|c|c|c|c|c|c|}
\hline \multirow{3}{*}{$\begin{array}{l}\text { Steps and } \\
\text { variables }^{\mathrm{a}}\end{array}$} & \multicolumn{6}{|c|}{ Neutral condition $(n=59)$} & \multicolumn{6}{|c|}{ Negative condition $(\mathrm{n}=61)$} \\
\hline & \multicolumn{2}{|l|}{ Step 1} & \multicolumn{2}{|l|}{ Step 2} & \multicolumn{2}{|l|}{ Step 3} & \multicolumn{2}{|l|}{ Step 1} & \multicolumn{2}{|l|}{ Step 2} & \multicolumn{2}{|l|}{ Step 3} \\
\hline & B & SE & B & SE & B & SE & B & SE & B & $\mathrm{SE}$ & B & SE \\
\hline Emotional Eating & 16.12 & 8.58 & 15.75 & 8.86 & $18.01^{*}$ & 8.56 & 4.31 & 6.72 & 2.54 & 6.89 & .97 & 6.96 \\
\hline Dietary Restraint & -1.86 & 5.98 & -2.76 & 6.05 & -2.55 & 5.81 & $-10.63^{*}$ & 5.02 & -8.72 & 5.18 & -9.85 & 5.23 \\
\hline Condition $^{\mathrm{b}}$ & & & -13.10 & 9.90 & -12.59 & 9.51 & & & 8.30 & 8.89 & 7.64 & 8.85 \\
\hline BIS-11 & & & -.83 & .53 & .15 & .66 & & & .53 & .44 & .02 & .60 \\
\hline Condition $\times$ BIS- 11 & & & & & $-2.34^{*}$ & 1.00 & & & & & 1.13 & .89 \\
\hline $\mathrm{R}^{2}$ & \multicolumn{2}{|c|}{.060} & \multicolumn{2}{|c|}{.131} & \multicolumn{2}{|c|}{.213} & \multicolumn{2}{|c|}{.075} & \multicolumn{2}{|c|}{.113} & \multicolumn{2}{|c|}{.139} \\
\hline$\Delta \mathrm{R}^{2}$ & \multicolumn{2}{|c|}{.060} & \multicolumn{2}{|c|}{.071} & \multicolumn{2}{|c|}{$.082^{*}$} & \multicolumn{2}{|c|}{.075} & \multicolumn{2}{|c|}{.039} & \multicolumn{2}{|c|}{.025} \\
\hline
\end{tabular}

a Note: B is the unstandardized regression coefficient.

b $\mathrm{CS}-$ is reference group.

$* p<.05$. 
production and food intake. The results indicate that the conditioning procedure in itself was successful; that is, differential acquisition of eating expectancy was found in both conditions. In other words, participants successfully learned associations between neutral cues and the presence or absence of food. With regard to the effects of this procedure, participants in both conditions also showed differential acquisition of desire to eat. These findings are in line with recent previous studies demonstrating Pavlovian appetitive conditioning in humans (Papachristou et al., 2013; Van den Akker et al., 2013; Van Gucht et al., 2010, 2013; Van Gucht, Vansteenwegen, Beckers et al., 2008; Van Gucht, Vansteenwegen, Van den Bergh et al., 2008). Contrary to our hypothesis, however, we could not demonstrate facilitated appetitive conditioning in participants in a negative compared to a neutral mood. When it comes to eating expectations, there were no differences in the differential acquisition of learned expectations to eat between the two mood conditions. The desire to eat showed however an interesting difference: Both mood conditions showed conditioned eating desires, but participants in the negative mood condition showed a significantly smaller differential response to the CSs at trial 4, meaning that their learned appetitive desire to eat was weaker than the learned appetitive desire in the neutral mood condition. Whether this is the start of a trend in appetitive conditioning responses or a temporary effect remains to be seen - our design consisted of only 4 trials. However, data on desire to eat immediately before the taste test suggest that a delayed learning effect might take place. Participants in the Negative CS+ condition reported a significantly higher desire to eat on an additional VAS-scale administered directly before the taste test, when the food was presented, compared to participants in the Negative CS- condition. No such difference was found between the Neutral CS+ and CS-groups. This finding suggests the successful learning of a differential response to desire to eat for participants in a negative compared to a neutral mood when presented with a large quantity of food after a conditioning procedure. Another study from our lab (Schyns, Roefs, Mulkens, \& Jansen, 2015) recently found an identical pattern: participants who underwent a food cue exposure training (i.e., prolonged exposure to the sight and smell of a well-liked food without consuming the food, aimed at extinguishing craving for and subsequent intake of that particular food) showed a strong decrease in desire to eat specifically after the exposure procedure, but before the start of a taste test. It could be that a delayed learning effect occurs in certain experimental groups, in which the effects of a conditioning or extinction procedure only become visible after a (short) break. Future studies could look into this by varying the time-interval of a post-conditioning or postexposure desire measure. As the common factor between the two studies is the presence of a large amount of food and the expectancy to eat, another possibility is that this presence of food and/ or expectancy to eat affects conditioned or extinguished desire to eat in the intended direction: increased desire to eat after a conditioning procedure aimed at increasing eating desires, and a decreased desire to eat after an extinction procedure aimed at reducing eating desires. Why such an increase or decrease would occur is a question for future research. Interestingly, in our study, the difference in desire to eat just before the taste test did not translate to a difference in actual food intake: The participants in the neutral and negative mood conditions consumed the same amount of food in the presence of the CS+ and CS-. It could be that exposure to large quantities of real food, which can be considered to be a very strong stimulus, overruled the experimentally conditioned associations, thereby nullifying their effects. Conditioning in real life is likely to be longer and stronger (lasting for months or years), which might be required for conditioned consumption effects.

With regard to salivation, we found no evidence for stronger conditioning in the negative compared to the neutral mood condition. Although salivation increased significantly over time, perhaps due to the exposure to and intake of food during the conditioning procedure, there were no differences in this increase with regard to the CS+ and CS- between the two mood conditions. When looking at the figure depicting salivary responses, it is interesting to note that there is some indication that participants in the negative mood condition displayed increased salivation in response to both the CS+ and CS-, whereas participants in the neutral mood condition showed such a response only when presented with the CS+. Why participants in a negative mood would show increased salivation in response to the CS- is unclear, especially considering the conditioned expectations to eat and the learned desire to eat that were both found in the negative mood condition. The inhibited salivary response to the $\mathrm{CS}$ - in the neutral mood condition would indicate that they have learned that the CS- would not be followed by food intake. The negative mood condition, on the other hand, did not show evidence of inhibited salivation to the CS-. In anticipation of more research on this topic, it could be that a negative mood generally leads to increased salivation, and that this general response is stronger than a conditioned inhibitory response. The few existing findings on mood states influencing salivation are mixed. Bulik, Lawson, and Carter (1996) reported a negative association between depression levels and salivation, while studies on the relationship between anxiety or stress and salivation have shown an increase (Rohleder, Wolf, Maldonado, \& Kirschbaum, 2006), a decrease (Bates \& Adams, 1968) or no salivary changes (Ben-Aryeh et al., 1985; Bulik et al., 1996). With our negative mood manipulation we cannot be sure exactly what kind of negative emotions we tapped into and how this might have influenced salivary responding.

Similar to Van den Akker et al. (2013) and Papachristou et al. (2013) we found no effect of impulsivity on expectancy, desire and salivation. However, whereas Van den Akker et al. (2013) found an increase in food intake for high-impulsive participants in response to the CS+ vs. CS-, we found a decrease. Our neutral-mood participants, who are comparable to the participants in the Van den Akker et al. (2013) study, showed lower food intake when presented with the CS+ compared to the CS-. Furthermore, in response to the $\mathrm{CS}+$, the neutral high-impulsive participants consumed less chocolate mousse than the neutral low-impulsive participants. These results are unexpected, as previous studies have generally been consistent in their findings that impulsivity is related to increased food intake (Guerrieri et al., 2008). It might be that the mixed results are due to differences in strength or type of impulsivity not captured by the BIS-11. Whether our findings are spurious or whether impulsivity can indeed inhibit food intake on some occasions is a question for further research.

Interestingly, we did not find any influence of emotional eater status on appetitive conditioning in a negative mood. It could be that our sample of normal-weight healthy students did not contain many, if any, true emotional eaters. Although our participants scored just above average according to the DEBQ norm-scores for female students (our sample $\mathrm{M}=2.74, \mathrm{SD}=.62$; norm-scores average is 2.612.66 (Van Strien, 2005)), previous studies with student and morbidly obese samples were unable to demonstrate emotional eating in these groups (Adriaanse, de Ridder, \& Evers, 2011; Bongers, Jansen, Havermans, Roefs, \& Nederkoorn, 2013; Bongers, Jansen, Houben, \& Roefs, 2013; Brogan \& Hevey, 2013; Evers, de Ridder, \& Adriaanse, 2009). These studies raise the question whether the DEBQ is a valid enough measure to identify emotional eaters. For now, there is no evidence that emotional eaters, as selected by the DEBQ are more susceptible to conditioned eating when emotional than nonemotional eaters. It could be of interest to investigate the influence of emotional eating on appetitive conditioning in a study in clinically identified samples of emotional eaters.

An elaboration on the design of the current study could test the idea that emotions act as an occasion setter in the development of emotional eating. In this case, the negative emotion would 
function as a CS that signals the occurrence of another CS-US association, and the CR only occurs when the CS-US association is accompanied by the negative emotion. Applied to the current study, this would entail that participants learn that the vase with flowers is followed by chocolate mousse intake only when a negative mood is present, and appetitive responses to the CS only arise when participants are in a negative mood. Another interesting endeavor for future research would be to investigate the first proposed pathway: it is the emotions themselves that become conditioned stimuli and elicit appetitive responses. Previous studies have shown that a variety of initially neutral cues can function as CSs in appetitive conditioning in humans, including objects, colours, and contexts (Birch, McPhee, Sullivan, \& Johnson, 1989; Dols, Willems, Van Den Hout, \& Bittoun, 2000; Thewissen, Havermans, Geschwind, van den Hout, \& Jansen, 2007; Thewissen, Van Den Hout, Havermans, \& Jansen, 2005; Van den Akker et al., 2013; Van Gucht, Vansteenwegen, Beckers et al., 2008; Van Gucht, Vansteenwegen, Van den Bergh et al., 2008). It seems plausible that emotions are no exception.

The present study benefits from several strengths, such as a manipulation check to ensure both a successful mood induction and successful conditioning (expectancy ratings), as well as the use of subjective, physiological and behavioural measures of conditioned responding. However, some limitations should also be noted. First, considering that our sample consisted of healthy female undergraduate students, we cannot generalize these results to other groups of interest, such as males or people with overweight or obesity. Second, although our sadness induction was very effective, we cannot be sure if any additional emotions were elicited in our participants (e.g., anger, nostalgia, remorse, anxiety). This seems to be an insurmountable issue however, as it would be very hard, if not impossible, to elicit one single, pure emotion in humans. If additional emotions were elicited, this could have influenced the subjective, physiological or behavioural measures. A third limitation concerns the stimuli we used. When participants were presented with the CS-, this was followed by an empty spoon. We chose this empty spoon to resemble the CS+ trials (in which a spoon with chocolate mousse was presented) as closely as possible, while still making clear to participants that no eating would occur. However, it is possible that the spoon was not neutral enough, given its typical association with eating, which caused participants to still create a link between the CS- vase and food. Although this did not influence conditioned expectancies and desires to eat, it could have influenced the null findings with regard to actual food intake. Fourth, although widely used in eating research with student samples, the BIS-11 has not been validated in this population.

To conclude, we are the first to demonstrate successful appetitive conditioning in neutral and negative moods. However, a negative mood does not seem to facilitate this conditioning process.

\section{References}

Adriaanse, M. A., de Ridder, D. T. D., \& Evers, C. (2011). Emotional eating. Eating when emotional or emotional about eating? Psychology \& Health, 26(1), 23-39.

Agras, W. S., \& Telch, C. F. (1998). The effects of caloric deprivation and negative affect on binge eating in obese binge-eating disordered women. Behavior Therapy, 29(3), 491-503.

Baker, T. B., Piper, M. E., McCarthy, D. E., Majeskie, M. R., \& Fiore, M. C. (2004). Addiction motivation reformulated. An affective processing model of negative reinforcement. Psychological Review, 111(1), 33.

Bates, J., \& Adams, D. (1968). The influence of mental stress on the flow of saliva in man. Archives of Oral Biology, 13(5), 593-596.

Ben-Aryeh, H., Roll, R., Kahana, L., Malberger, E., Szargel, R., \& Gutman, D. (1985) Saliva as an indicator of stress. International Journal of Psychosomatics, 32(3), 3-8.

Birch, L., McPhee, L., Sullivan, S., \& Johnson, S. (1989). Conditioned meal initiation in young children. Appetite, 13(2), 105-113.

Boddez, Y., Baeyens, F., Luyten, L., Vansteenwegen, D., Hermans, D., \& Beckers, T. (2013). Rating data are underrated. Validity of US expectancy in human fear conditioning. Journal of Behavior Therapy and Experimental Psychiatry, 44(2), 201-206.
Bongers, P., Jansen, A., Havermans, R., Roefs, A., \& Nederkoorn, C. (2013). Happy eating. The underestimated role of overeating in a positive mood. Appetite, 67 74-80.

Bongers, P., Jansen, A., Houben, K., \& Roefs, A. (2013). Happy eating. The single target implicit association test predicts overeating after positive emotions. Eating Behaviors, 14, 348-355.

Brogan, A., \& Hevey, D. (2013). Eating styles in the morbidly obese. Restraint eating, but not emotional and external eating, predicts dietary behaviour. Psychology E Health, 28(6), 714-725.

Bulik, C. M., Lawson, R. H., \& Carter, F. A. (1996). Salivary reactivity in restrained and unrestrained eaters and women with bulimia nervosa. Appetite, 27(1), 15-24.

Chua, J. L., Touyz, S., \& Hill, A. J. (2004). Negative mood-induced overeating in obese binge eaters. An experimental study. International Journal of Obesity, 28(4), 606-610.

Coletta, M., Platek, S., Mohamed, F. B., van Steenburgh, J. J., Green, D., \& Lowe, M. R. (2009). Brain activation in restrained and unrestrained eaters. An fMRI study. Journal of Abnormal Psychology, 118(3), 598.

Cools, J., Schotte, D. E., \& McNally, R. J. (1992). Emotional arousal and overeating in restrained eaters. Journal of Abnormal Psychology, 101(2), 348-351.

Corr, P. J. (2004). Reinforcement sensitivity theory and personality. Neuroscience $\mathcal{E}$ Biobehavioral Reviews, 28(3), 317-332.

Corr, P. J., Pickering, A. D., \& Gray, J. A. (1995). Personality and reinforcement in associative and instrumental learning. Personality and Individual Differences, 19(1), 47-71.

Dols, M., Willems, B., Van Den Hout, M., \& Bittoun, R. (2000). Smokers can learn to influence their urge to smoke. Addictive Behaviors, 25(1), 103-108.

Evers, C., de Ridder, D. T. D., \& Adriaanse, M. A. (2009). Assessing yourself as an emotional eater. Mission impossible? Health Psychology, 28(6), 717-725.

Greeno, C. G., \& Wing, R. R. (1994). Stress-induced eating. Psychological Bulletin, 115(3), 444.

Guerrieri, R., Nederkoorn, C., \& Jansen, A. (2008). The effect of an impulsive personality on overeating and obesity. Current state of affairs. Psihologijske teme, 17(2), 265-286.

Hays, N. P., \& Roberts, S. B. (2008). Aspects of eating behaviors 'disinhibition' and 'restraint' are related to weight gain and BMI in women. Obesity, 16(1), 52-58.

Heatherton, T., Herman, C., \& Polivy, J. (1991). Effects of physical threat and ego threat on eating behavior. Journal of Personality and Social Psychology, 60(1), 138

Hepworth, R., Mogg, K., Brignell, C., \& Bradley, B. P. (2010). Negative mood increases selective attention to food cues and subjective appetite. Appetite, 54(1), 134142.

Jansen, A. (1998). A learning model of binge eating. Cue reactivity and cue exposure. Behaviour Research and Therapy, 36, 257-272.

Jansen, A., Havermans, R. C., \& Nederkoorn, C. (2011). Cued overeating. In: V. R. Preedy, R. R. Watson, \& C. R. Martin (Eds.), Handbook of behavior, food and nutrition (pp. 1431-1443). New York: Springer.

Karos, K., Meulders, A., \& Vlaeyen, J. W. (2014). Threatening social context facilitates pain-related fear learning. The Journal of Pain, doi:10.1016/j.jpain.2014.11.014.

Lovibond, P. F., \& Shanks, D. R. (2002). The role of awareness in Pavlovian conditioning. Empirical evidence and theoretical implications. Journal of Experimental Psychology. Animal Behavior Processes, 28(1), 3.

Loxton, N. J., Dawe, S., \& Cahill, A. (2011). Does negative mood drive the urge to eat? The contribution of negative mood, exposure to food cues and eating style. Appetite, 56(2), 368-374.

Macht, M., \& Dettmer, D. (2006). Everyday mood and emotions after eating a chocolate bar or an apple. Appetite, 46(3), 332-336.

Macht, M., \& Mueller, J. (2007). Immediate effects of chocolate on experimentally induced mood states. Appetite, 49(3), 667-674.

Paisey, T. J., \& Mangan, G. L. (1988). Personality and conditioning with appetitive and aversive stimuli. Personality and Individual Differences, 9(1), 69-78.

Papachristou, H., Nederkoorn, C., Beunen, S., \& Jansen, A. (2013). Dissection of appetitive conditioning. Does impulsivity play a role? Appetite, 69, 46-53.

Patel, K. A., \& Schlundt, D. G. (2001). Impact of moods and social context on eating behavior. Appetite, 36(2), 111-118.

Patton, J. H., Stanford, M. S., \& Barratt, E. S. (1995). Factor structure of the Barratt impulsiveness scale. Journal of Clinical Psychology, 51(6), 768-774.

Polivy, J., \& Herman, C. P. (2002). Causes of eating disorders. Annual Review of Psychology, 53(1), 187-213.

Rohleder, N., Wolf, J. M., Maldonado, E. F., \& Kirschbaum, C. (2006). The psychosocial stress-induced increase in salivary alpha-amylase is independent of saliva flow rate. Psychophysiology, 43(6), 645-652.

Schneider, K. L., Appelhans, B. M., Whited, M. C., Oleski, J., \& Pagoto, S. L. (2010). Trait anxiety, but not trait anger, predisposes obese individuals to emotional eating. Appetite, 55(3), 701-706.

Schyns, G., Roefs, A., Mulkens, S., \& Jansen, A. (2015). Expectancy violation, reduction of food cue reactivity and less eating in the absence of hunger after one food cue exposure session for overweight and obese women. Manuscript submitted for publication.

Small, D. M., Zatorre, R. J., Dagher, A., Evans, A. C. \& Jones-Gotman, M. (2001). Changes in brain activity related to eating chocolate from pleasure to aversion. Brain: A Journal of Neurology, 124(9), 1720-1733.

Thewissen, R., Havermans, R. C., Geschwind, N., van den Hout, M., \& Jansen, A. (2007) Pavlovian conditioning of an approach bias in low-dependent smokers. Psychopharmacology, 194(1), 33-39.

Thewissen, R., Van Den Hout, M., Havermans, R. C., \& Jansen, A. (2005). Contextdependency of cue-elicited urge to smoke. Addiction (Abingdon, England), 100(3) 387-396. 
Van den Akker, K., Jansen, A., Frentz, F., \& Havermans, R. C. (2013). Impulsivity makes more susceptible to overeating after contextual appetitive conditioning. Appetite, $70,73-80$

Van Gucht, D., Baeyens, F., Hermans, D., \& Beckers, T. (2013). The inertia of conditioned craving. Does context modulate the effect of counterconditioning? Appetite, 65, 51-57.

Van Gucht, D., Baeyens, F., Vansteenwegen, D., Hermans, D., \& Beckers, T. (2010). Counterconditioning reduces cue-induced craving and actual cue-elicited consumption. Emotion (Washington, D.C.), 10(5), 688-695.

Van Gucht, D., Vansteenwegen, D., Beckers, T., \& Van Den Bergh, O. (2008). Return of experimentally induced chocolate craving after extinction in a different context. Divergence between craving for and expecting to eat chocolate. Behaviour Research and Therapy, 46(3), 375-391.

Van Gucht, D., Vansteenwegen, D., Van den Bergh, O., \& Beckers, T. (2008). Conditioned craving cues elicit an automatic approach tendency. Behaviour Research and Therapy, 46(10), 1160-1169.

Van Strien, T. (2005). Nederlandse vragenlijst voor eetgedrag 2005. Handleiding en verantwoording [Manual of the Dutch Eating Behavior Questionnaire 2005]. Amsterdam: Boom test uitgevers.
Velázquez-Sánchez, C., Ferragud, A., Moore, C. F., Everitt, B. J., Sabino, V., \& Cottone, P. (2014). High trait impulsivity predicts food addiction-like behavior in the rat. Neuropsychopharmacology, 39(10), 2463-2472.

Vuoskoski, J. K., \& Eerola, T. (2012). Can sad music really make you sad? Indirect measures of affective states induced by music and autobiographical memories. Psychology of Aesthetics, Creativity, and the Arts, 6(3), 204.

Wallis, D. J., \& Hetherington, M. M. (2004). Stress and eating. The effects of ego-threat and cognitive demand on food intake in restrained and emotional eaters. Appetite, 43(1), 39-46.

Wardle, J. (1990). Conditioning processes and cue exposure in the modification of excessive eating. Addictive Behaviors, 15(4), 387-393.

Zinbarg, R., \& Mohlman, J. (1998). Individual differences in the acquisition of affectively valenced associations. Journal of Personality and Social Psychology, 74(4), 1024.

Zinbarg, R., \& Revelle, W. (1989). Personality and conditioning. A test of four models. Journal of Personality and Social Psychology, 57(2), 301. 